\section{ESTUDO SOBRE A CORIZA INFECCIOSA DAS GALINHAS. I. CARACTERES CULTURAIS, BIOQUIIMICOS E SOROLÓGICOS DE 17 AMOSTRAS DE HAEMOPHILUS ISOLADAS NO BRASIL*}

\author{
HIDEMI NARITA \\ Estagiário, docente voluntário \\ OSMANE HIPÓLITO \\ Professor Titular \\ Assessor do D.T.C. Embrapa, Brasilia \\ JOSÉ AMÉRICO BOTTINO \\ Professor Livre Docente \\ Faculdade de Medicina Veterinária e \\ Zootecnia da USP
}

NARITA, H.; HIPÓLITO, O.; BOTTINO, J.A. Estudo sobre a coriza infecciosa das galinhas. I. Caracteres culturais, bioquímicos e sorológicos de 17 amostras de Haemophilus isoladas no Brasil. Rev. Fac. Med. vet. Zootec. Univ. S.Paulo, 17(1/2):29-31, 1980.

RESUMO: Dezessete amostras de organismos do gênero Haemophilus isoladas de galinhas com sintomas clínicos de coriza infecciosa foram obtidas do seio infra-orbitário de aves com infecção natural. Os organismos cresceram bem no meio Ägar-20 e no meio líquido CMI-20 suplementado com $5 \%$ de soro de galinha e $2 \%$ de extrato de fermento. Esses organismos microaerófilos exigiam o fator $V$ mas não o fator $\mathrm{X}$. Cinco amostras exigiram soro de galinha além do fator V para o crescimento no mejo Ágar-20. Não houve crescimento em passagens seriadas no meio Agar-20 em condições aerobiose. O Staphylococcus aureus foi usado como cultura alimentadora nos isolamentos. Todas as amostras eram catalase e indol negativas. Nenhuma delas produziu indol, $\mathrm{H} 2 \mathrm{~S}$ ou gás nem liquidez a gelatina. Todas reduziram nitratos a nitritos. Eram Gram negativas, imóveis e apresentavam bipolaridade. Todas fermentaram glucose, manose, fructose, sacarose e destrina mas não fermentaram arabinose, ramnose, galactose, lactose, trealose, rafinose, inulina, adonitol, dulcito, inosito e salicina. Algumas fermentaram xilose, maltose, manitol e sorbitol. Quinze amostras isoladas foram estudadas sorologicamente e dividi das em dois grupos. Oito das amostras representando um tipo sorológico fermentaram a xilose mas sete representando um segundo tipo sorológico deixaram de fazê-lo. Os resultados dos estudos coincidiram bastante com os de outros autores. Pelo fato de não exigirem o fator X mas sim o V, as 17 a mostras isoladas e aqui estudadas deve riam ser denominadas Haemophylus paragallinarum BIBERSTEIN e WHITE, 1969.

UNITERMOS: Coriza infecciosa, galinhas*, Haemophilusgallinarum * Haemophilus paragallinarum *

Trabalho apresentado ao XVI Congresso Mundial de Avicultura, Rio de Janeiro, 1979.

Trabalho realizado com auxílio do Conselho Nacional de Desenvolvimento Científico e Tecnológico (CNPq) e da Fundação Cargill.

\section{INTRODUÇÃO}

$\mathrm{O}$ agente da coriza infecciosa das galinhas foi primeiramente relatado por DE BLIECK $^{6}$ na Holanda e por NELSON 11 nos Estados Unidos, em 1932. Durante as últimas três décadas, a partir destes trabalhos, muitos aspectos da coriza infecciosa foram estudados no mundo por muitos investigadores, entre eles ADLER e PAGE1, BEACH e SCHALM $^{2}$, BORNSTEIN e SAMBERG ${ }^{4}$, CLARK e GODFREY5, DELAPLANE e Cols ${ }^{7}$., YAMAMOTO e SOMERSET 13 , KATO e TSUBAHARA ${ }^{10}$, HINZ ${ }^{9}$, etc.

As características culturais, bioquímicas e sorológicas das amostras de Haemophilus isoladas de galinhas foram estudadas e relatadas por BORNSTEIN e SAMBERG 4 em Israel, PAGE 12, nos Estados Unidos, KATO e TSUBAHARA $^{10}$, no Japão e HINZ ${ }^{9}$, na Aiemanha.

A ocorrência da coriza infecciosa tem sido frequente no Brasil por muitos anos e graças às características clínicas bastante típicas com que a doença ocorre nas galinhas, é facilmente reconhecida, porém seu agente etiológico não havia sido ainda estudado entre nós. É uma das mais importantes doenças das aves no presente, ocasionando elevadas perdas econômicas, sem contar as complicações que podem advir resultantes da associação com os agentes da chamada doença respiratória crônica (DRC) das galinhas. Neste relatório, os aspectos globais das características das amostras isoladas foram estudados como contribuição para reduzir as perdas causadas pela coriza infecciosa.

\section{MATERIAL E MÉTODOS}

Dezessete amostras de Haemophilus sp. foram isoladas durante os anos 1976-77 a partir de material coletado diretamente do seio infra orbitário de galinhas com sintomas de coriza infecciosa. Como meios de cultura básicos para o isolamento e manutenção das culturas foram usados meios líquido e sólido preparados com infusão de carne de galinha enriquecidos com soro de galinha e denominados meios CMI-20 e Ágar-20, respectivamente. Como fator V foram utilizados o sal dissódico reduzido de B-nicotinamida adenina dinucleotídio (Kohjin) e o extrato de fermento. A hemina, utilizada como fator X, foi obtida da Sigma Chemical. Para os estudos sorológicos foram preparados soros imunes em coelhos inoculados com uma suspensão bacteriana ajustada em transmitancia $(60 \% \mathrm{~T})$ com auxílio de um espectrofotômetro Coleman Jr. modêlo 6-065 em comprimento de onda de 540 mu. Foram utilizados os métodos de aglutinação lenta e rápida para a determinação dos sorotipos de Haemophilus sp.

\section{RESULTADOS E DISCUSSÃO}

Os resultados encontrados (Tabelas 1, 2 e 3) no estudo de 17 amostras de Haemophilus sp. isoladas no Brasil de galinhas com coriza infecciosa coincidem em sua maioria com aqueles constatados por HINZ8,9.

Os organismos crescem bem no meio Ágar-20 e no meio líquido CMI-20 suplementado com $5 \%$ de soro de galinha e $2 \%$ de extrato de fermento. Esses organismos microaerófilos exigiram o fator $\mathrm{V}$ mas não o fator $\mathrm{X}$. Cinco amostras exigiram soro de galinha além do fator $\mathrm{V}$ para o crescimento no meio Ágar-20. Não houve crescimento em passagens seriadas no meio Ágar-20 em condiçōes de aerobiose. O Staphylococcus aureus foi usado como cultura alimentadora nos isolamentos. Todas as amostras eram catalase e indol negativas. Nenhuma delas produziu indol, H2S ou gás 
liquefez a gelatina. Todas reduziram nitratos a nitritos. Eram Gram-negativos, imóveis e apresentavam bipolaridade. Em nossa investigação somente foram estudadas culturas catalase-negativas e patogênicas mas PAGE 12 e HINZ 8,9 , incluiram também amostras catalase-positivas e não patogênicas. A diferenciação com respeito à patogenicidade das amostras é fácil quando se toma por base a prova da catalase.

Das 23 amostras estudadas por HINZ8,9, seis exigiram soro de galinha além do fator $\mathrm{V}$ e o mesmo aconteceu com cinco das nossas amostras. Entretanto, não foi possível no presente estudo determinar quais os fatores presentes no soro de galinha que são exigidos para o crescimento do $\mathrm{H}$. paragallinarum. $\mathrm{E}$ bastante interessante notar que, conforme foi também observado por PAGE 12 os organismos do gênero Haemophilus que exigiram o fator $\mathrm{V}$ adicionado ao meio Ägar- 20 cresceram bem no caldo quando o mesmo recebeu também $5 \%$ de soro de galinha.

O estudo de 15 amostras pela prova de soro-aglutinação cruzada mostrou a existência de dois grupos sorológicos distintos. Com base nesses estudos as demais amostras isoladas foram também identificadas sorologicamente. Verificou-se ainda que havia acentuada diferença na velocidade de sedimentação da mistura antígeno-anticorpo após a aglutinação e nos títulos aglutinantes entre as amostras dos dois grupos sorológicos.

De acordo com os resultados pode-se concluir pela identidade entre os nosso sorotipo I e o sorotipo A de PAGE12 e HINZ8,9. Pode-se tambem assumir a identidade sorológica entre o nosso grupo II e o sorotipo B dos autores citados.

As amostras pertencentes aos dois sorotipos parecem possuir a mesma virulência para produzir a doença experimental em aves susceptiveis. $O$ comportamento das dezessete amostras isoladas permite classificá-las como Haemophilus paragallinarum BIBERSTEIN e WHITE, 1969.

Com respeito à fermentação de carbohidratos, todas fermentaram glucose, manose, fructose, sacarose e destrina, mas não fermentaram arabinose, ramnose, galactose, lactose, trealose, rafinose, inulina, adonitol, dulcitol, inositol e salicina. Algumas fermentaram xilose, maltose, manitol e sorbitol.

Esses resultados coincidiram bastante com os dados citados por HINZ 8,9. Em primeiro lugar, dez de nossas amostras fermentaram a xilose, o mesmo acontecendo com seis do autor citado. Na prova de fermentação da galactose houve completa coincidência. Mas KATO e TSUBAHARA ${ }^{10}$, PAGE $^{2}$ e BORNSTEIN e SAMBERG 4 relataram que nenhuma de suas amostras fermentou a xilose e algumas delas ou todas fermentaram a galactose.

\section{CONCLUSÕES}

As dezessete amostras de organismos isolados do seio infra-orbitário de galinhas com doença natural clinicamente diagnosticada como coriza infecciosa exigiam o fator $\mathrm{V}$ mas não o fator $\mathrm{X}$ para o seu crescimento. Isso leva à conclusão de que tais organismos são idêntidos ao Haemophilus paragallinarum BIBERSTEIN e WHITE ${ }^{3}, 1969$.

Sob o ponto de vista sorológico, as dezessete amostras estudadas foram divididas em dois grupos com base no método da soroaglutinação. $O$ achado curioso foi que a fermentação da xilose, pelo menos no presente estudo, serviu para diferenciar os dois grupos.
TABELA I. Exigencias nutricionass de 17 amostras de Haemophilus isoladas de galinha com coriza infecciosa Incubação em

Meio Ägar-20
suplementado com
Aero- Anaerobiose robiose

1. Cultura alimentadora $\mathrm{S}$. aureus $0 / 17$ *) $^{*} 17 / 17$

2. 10 ug NADH por $\mathrm{ml}$

3. $10 \%$ extrato de fermento

4. 10 ug de hemina por $\mathrm{m}$ !

$5.5 \%$ de soro de galinha $0 / 17 \quad 12 / 17$ $0 / 17 \quad 12 / 17$ $0 / 17 \quad 0 / 17$ $0 / 17 \quad 0 / 17$

6. $10 \mathrm{ug} \mathrm{NADH} / \mathrm{ml}+10$ ug hemina $0 / 17 \quad 12 / 17$

10 ug NADH $/ \mathrm{ml}+5 \%$ soro de galinha $\quad 0 / 17 \quad 17 / 17$

8. $10 \%$ extr. fermento $+10 \%$ hemina $\quad 0 / 17 \quad 12 / 17$

9. $10 \%$ extr. fermento $+5 \%$ soro galinha $\quad 0 / 17 \quad 17 / 17$

10 Controle (sem suplementação)

(*) = NO culturas positivas/ NO culturas testadas.

TABELA 2: Caracteres bioquimicos de 17 amostras de Haemophilus isoladas de galinhas com coriza infecciosa.

$\begin{array}{lc}\quad \text { Provas } & \text { Resultado } \\ \text { bioquímicas } & 10 / 17\left(^{\circ}\right) \\ \text { 1. Xilose } & 15 / 17 \\ \text { 2. Maltose } & 6 / 17 \\ \text { 3. Sorbitol } & 12 / 17 \\ \text { 4. Manitol } & 0 / 17 \\ \text { 5. Indol } & 0 / 17 \\ \text { 6. Catalase } & 17 / 17 \\ \text { 7. Redução de nitratos } & 0 / 17 \\ \text { 8. Formação de gás } & 0 / 17 \\ \text { 9. Liquefação da gelatina } & 0 / 17 \\ \text { 10. Produção de H2S } & \end{array}$

(*) NO de culturas positivas ou ligeiramente positivas sobre NO de culturas testadas.

TABELA 3: Relação entre fermentação de xilose e sorotipos de 15 amostras de Haemophilus isoladas de casos de coriza infecciosa.

\begin{tabular}{|c|c|c|c|}
\hline $\begin{array}{c}\text { Amostra ou } \\
\text { Antígeno }\end{array}$ & $\begin{array}{c}\text { Fermentação } \\
\text { da Xilose }\end{array}$ & $\begin{array}{c}\text { Sorotipo I } \\
\text { Amostra B - 2 }\end{array}$ & $\begin{array}{c}\text { Sorotipo II } \\
\text { Amostra S-4 }\end{array}$ \\
\hline $\mathrm{M}-1$ & - & + & - \\
\hline$M-2$ & - & + & - \\
\hline$B-1$ & - & + & \\
\hline$B-2$ & - & + & - \\
\hline G & - & + & - \\
\hline$M-3$ & - & + & - \\
\hline $\mathrm{T}$ & - & + & - \\
\hline$B-3$ & + & - & + \\
\hline$B-4$ & + & - & + \\
\hline$S-1$ & + & - & + \\
\hline$S-2$ & + & - & + \\
\hline $\mathrm{S}-3$ & + & - & + \\
\hline$S-4$ & + & - & + \\
\hline$M-4$ & + & - & + \\
\hline$M-5$ & + & - & + \\
\hline & gativo & + Positiv & \\
\hline
\end{tabular}


Estudo sobre a Coriza Infecciosa das Galinhas. I. Caracteres Culturais, Bioquímicos e Sorológicos de- 31 17 amostras de Haemophilus isoladas no Brasil.

NARITA, H.; HIPÓLITO, O.; BOTTINO, J.A. Studies on infectious coryza of chickens. I. Cultural biochemical and serological characteristics of 17 strains of Haemophilus isolated in Brazil. Rev. Fac. Med. vet. Zootec. Univ. S. Paulo, 17 (1/2): 29-31. 1980 .

SUMMARY: Seventeen strains of organisms of the gemus Haemophilus were isolated from the infra-orbital sinuses of chickens with clinical symptoms of infectious coryza. The isolates grew well in the Agar-20 medium and in the CMI-20 liquid medium supplemented with 5 per cent chicken serum and 2 per cent yeast extract. These organisms required factor $\mathrm{V}$ but not factor $\mathrm{X}$ for growth in Agar -20 medium. No growth was obtained in serial passages in Agar-20 medium in aerobic conditions. Staphylococcus aureus was used as feeding culture for isolation purposes.

All strains were catalase and indol negative. None produced indol, $\mathrm{H} 2 \mathrm{~S}$ and gas or liquefied gelatin. All reduced nitrates to nitrites and were Gram negative, immotile and presented bipolarity. All fermented glucose, mannose, fructose, saccharose and dextrin but not arabinose, rhamnose, galactose, lactose, trehalose, raffinose, inulin, adonitol, dulcitol, inositol and salicin. A few fermented xylose, maltose, mannitol and sorbitol.

Nine strains were studied serologically and divided into two groups. All strains of one serological group fermented xylose while none of the other group did it.

Sinse all strains studied did not require factor $\mathrm{X}$ but only factor $V$ they should be classified as Haemophilus paragallinarum, BIBERSTEIN e WHITE, 1969.

UNITERMS: Infectious coryza, chickens*; Haemophilus gallinarum * Haemophilus paragallinarum* .

\section{REFERÊNCIAS BIBLIOGRÄFICAS}

I - ADLER, H.E. \& PAGE, L.A. Haemophilus infections in chickens. II. The pathology of the respiratory tract. Avian Dis., 6:1-6,1961.

2 - BEACH, J.R. \& SCHALM, O.W. Studies of the chemical manifestation and transmissibility of infectious coryza of chickens. Poultry Sci., 15: 466$70,1936$.

3 - BIBERSTEIN, E.L. \& WHITE, D.C. A proposal for the establishment of two new Haemophilus species. J. Med. Microb., 2: 75-78, 1969.

4 - BORNSTEIN, S. \& SANBERG, Y. The therapeutic effect o streptomycin on infectious coryza of chickens caused by Haemophilus gallinarum. II. Isolation and culture of Haemophilus gallinarum and some of its biochemical reactions. Amer. J. Vet. Res., $15: 612-16,1954$.

5 - CLARK, D.S. \& GODFREY, J.F. Studies of on inactivated Haemophilus gallinarum vaccine for immunization of chickens against infectious coryza. Avian Dis., 5 : 37-47, 1961.

6 - DEBLIECK, L.A A haemoglobinophilic bacterium as the cause of contagious catarrh of the fowl. Vet. J., $88: 9-13,1932$.

7 - DELAPLANE, J.P; ERWIN, L.E. \& STUART, H. O. The isolation of a haemophilus bacillus in pure culture and the reactions of chickens to intranasal inoculation the reof. J. Agr. Res., $52: 377-83$, 1936.
8 - HINZ, K.H. Beitrag zur differenziarung von Haemophilus :stämmen aus Hühnern. I. Mitteilung: Kulturelle und biochemische untersuchungen. Avian. Path., 2(3): 211-29, 1973.

9 - HINZ, K. H. Beitrag zur differenzierung von Haermophilus stämmen aus Hühnern. II. Mitteilung: Serologische untersuchungen in objekttager - agglutinations - Test. Avian Path., 2 : (4) 269-78, 1973 a.

10 - KATO, K. \&. TSUBAHARA, H. Infectious coryza of chickens. II. Identification of isolates. Bull. Nat. Inst. Animal Health, $45: 21-26,1962$.

11 - NELSON, J. B. Studies on an uncomplicated coryza of the domestic fowl. I. The isolation of a bacillus which produces a nasal discharge. J. Exp. Med., 58: 289,1933

12 - PAGE, L.A. Haemophilus infections in chickens. I. Characteristics of 12 Haemophilus isolates recovered from diseased chickens. Amer. J. Vet. Res., 23: 85-95, 1962.

13 - YAMAMOTO, R.\& SOMERSETT, D.T. Antibody response in chickens to infection with Haemophilus gallinarum. Avian Dis., 8: 441 -53, 1964.

Recebido para publicação em: 24/03/80 Aprovado para publicação em: 18/08/80 